\title{
REFLEX SYMPATHETIC DYSTROPHY AFFECTING THE KNEE
}

\author{
MICHAEL M. KATZ, DAVID S. HUNGERFORD
}

\author{
From Johns Hopkins University School of Medicine, Baltimore
}

\begin{abstract}
Thirty-six patients with reflex sympathetic dystrophy primarily affecting the knee were reviewed. Injuries or operation about the patellofemoral joint triggered its onset in $64 \%$ of patients. Co-existent mechanical derangement of the knee was present in $64 \%$ of patients.

Those patients who underwent sympathetic blockade or sympathectomy within one year of onset of symptoms had significantly better pain and function scores than those in whom intervention was later. Early diagnosis remains the key to successful management. Surgery for co-existent mechanical derangement in the affected knee should not be performed until the syndrome is controlled.
\end{abstract}

Reflex sympathetic dystrophy is an exaggerated sympathetic response to an injured limb. The usual features are pain (intense or unduly prolonged), vasomotor disturbances, delayed functional recovery, and trophic changes (Toumey 1948; De Takats 1965; Shutzer and Gossling 1984).

Much of the confusion surrounding the disorder is related to the many different labels applied to it. Mitchell, Morehouse and Keen (1864) first vividly described the most dramatic manifestation, which was later termed "causalgia". Sudeck's atrophy, traumatic angiospasm, algodystrophy, minor causalgia and mimocausalgia all refer to various conditions that constitute the spectrum of sympathetic over-response to injury (Spurling 1930; Patman, Thompson and Persson 1973; Ficat and Hungerford 1977; Kozin et al. 1981; Lagier, Boussina and Mathies 1983). Evans (1946) used the term reflex sympathetic dystrophy as a label to encompass the broad spectrum of the disorder.

Spurling (1930) was the first to treat the syndrome successfully by sympathectomy. Previously many severely affected patients were chronic invalids or suffered from narcotic addiction; suicide was not uncommon.

Theories concerning the pathogenesis of reflex sympathetic dystrophy have sought to explain the universal characteristic of pain with sympathetic activity far exceeding the amount expected for a given injury. Livingston's (1943) theory involves a triad of (1) chronic peripheral sensory nerve irritation, (2) an abnormal

M. M. Katz, MD, Attending Physician

8220 Walnut Hill Lane, Suite 61511 Dallas, Texas 75231, USA.

D. S. Hungerford, MD, Professor

Department of Orthopaedic Surgery, Johns Hopkins University School of Medicine, Division of Arthritis Surgery, Good Samaritan Hospital, 5601 Loch Raven Boulevard, Baltimore, Maryland 21239, USA.

Requests for reprints should be sent to Professor D. S. Hungerford. (C) 1987 British Editorial Society of Bone and Joint Surgery $0301-620 \mathrm{X} / 87 / 5094 \$ 2.00$ activity state in the internuncial neuronal pool, producing a burst of activity in the cord, and (3) continuous stimulation of the sympathetic motor efferent fibres. The gate-control theory of pain proposed by Melzack and Wall (1965) suggests that selective activation of small C fibres in the substantia gelatinosa "opens the gate" and results in unchecked transmission of pain as well as creating the potential for summation. Doupe, Cullen and Chance (1944), however, postulated a peripheral mechanism: in this theory, an artificial synapse develops between sensory afferents and sympathetic efferents which in turn permits direct cross-stimulation and cycle formation. Shutzer and Gossling (1984) in a recent review concluded that the pathogenesis of this syndrome is most likely to be a combination of peripheral and centrally mediated factors.

Most clinical series of reflex sympathetic dystrophy have either intermingled patients with affected upper and lower limbs or have discussed the characteristics and management of the upper limb only (Toumey 1948; Kleinert et al. 1973; Patman et al. 1973; Lankford and Thompson 1977; Kozin et al. 1981). However, sporadic reports involving primarily the knee have been published (Toumey 1948; Ficat and Hungerford 1977; Arlet et al. 1981; Lagier et al. 1983). Toumey (1948) reported on 31 patients in one of whom the onset followed a twisting injury to the knee. Ficat and Hungerford (1977) discussed the course of sympathetic dystrophy affecting the knee in some 14 patients who underwent bone marrow pressure studies of the patella as a diagnostic measure. Arlet et al. (1981) reported 16 cases and described the pathological findings of bone biopsy specimens. As general awareness of the syndrome has increased, cases which arise following trauma to the knee have been more widely recognised.

The purpose of this paper is to present the spectrum of symptoms and signs of a group of patients with reflex sympathetic dystrophy whose principal manifestations 
were about the knee and which were prompted by injury. In addition, the clinical course of the disorder and its response (or lack of response) to treatment will also be presented.

\section{METHODS AND MATERIALS}

The diagnostic criteria for inclusion in the study were strict. Each patient suspected of having the syndrome had to complain of intense, prolonged pain and to have delayed functional recovery following an injury or surgical procedure to the knee. Vasomotor disturbances or hypersensitivity were also required. All patients had to have undergone lumbar sympathetic blockade as a diagnostic test with at least transient partial relief of symptoms, associated with a rise in skin temperature of the extremity; if this was negative they were excluded from the study. Finally, at least two years' follow-up from the time of diagnosis was required.

Thirty-six patients fulfilled these requirements and were included in the study. Case records and radiographs were reviewed. Thermograms obtained at the time of diagnosis, using a standard technique (AGA thermovision) and performed on both lower limbs (Uematsu et al. 1981), were available in eight patients. Technetium pyrophosphate bone imaging was available in 13 patients.

Patients were generally examined at intervals of three to six months until their symptoms improved or remained stable, or they left the locality. A telephone interview was conducted with all patients. Sixteen of 36 patients $(44 \%)$ had been examined by the senior author within one year of the follow-up survey. A 50-point pain and function rating scale for the knee was used to evaluate the level of discomfort and disability both at the time of diagnosis and at follow-up (Table I).

Table I. A 50-point rating system for pain and dysfunction of the knee in reflex sympathetic dystrophy

\begin{tabular}{ll}
\hline Clinical description & Point rating \\
\hline $\begin{array}{l}\text { A. Frequent rest pain. Severe pain with any activity, thus } \\
\text { preventing weight-bearing. Analgesics stronger than } \\
\text { aspirin required. Cannot perform routine activities } \\
\text { because of knee pain. }\end{array}$ & 0 \\
$\begin{array}{l}\text { B. Common rest pain. Moderately severe pain with } \\
\text { almost any activity. Heavy dependence upon weight- } \\
\text { bearing assistive devices. Unable to do most work } \\
\text { because of pain. Unable to do most housework or } \\
\text { even simple activities. }\end{array}$ & 10 \\
$\begin{array}{l}\text { C. Less frequent rest pain. Routine activities moderately } \\
\text { restricted. May require mild or narcotic analgesics. }\end{array}$ & 25 \\
$\begin{array}{l}\text { D. Peforms most routine activities with slight or tolerable } \\
\text { pain. Occasional mild, non-narcotic analgesics or anti- } \\
\text { inflammatory medications. }\end{array}$ & 40 \\
E. No discomfort with routine activity. Excessive \\
activity provokes discomfort. Rarely takes analgesics \\
or anti-inflammatory medication.
\end{tabular}

Table II. Event triggering reflex sympathetic dystrophy in the 36 patients

\begin{tabular}{lcc}
\hline & Number & Percentage \\
\hline Surgery & 15 & 41 \\
Anterior knee trauma & 17 & 47 \\
Twisting injury & 3 & 8 \\
Crush injury & 1 & 3 \\
\hline
\end{tabular}

Table III. Surgical procedures triggering onset of reflex sympathetic dystrophy

\begin{tabular}{lll}
\hline Procedure & $\begin{array}{l}\text { Pre-operative } \\
\text { diagnosis }\end{array}$ & $\begin{array}{l}\text { Number of } \\
\text { patients }\end{array}$ \\
\hline Total knee replacement & Osteoarthritis & 5 \\
$\begin{array}{l}\text { Arthrotomy, lateral release, } \\
\text { partial patellar chondrectomy }\end{array}$ & $\begin{array}{l}\text { Patellofemoral } \\
\text { tracking disorder }\end{array}$ & 4 \\
Patellectomy & Chondromalacia & 1 \\
High tibial osteotomy & Osteoarthritis & 1 \\
$\begin{array}{l}\text { Medial meniscectomy } \\
\text { Tibial tubercle elevation } \\
\text { (Maquet) }\end{array}$ & Meniscal tear & 2 \\
Medial arthrotomy & Chondromalacia & 1 \\
\hline
\end{tabular}

\section{RESULTS}

Epidemiology. Of the 36 patients in the study, $11(31 \%)$ were male and $25(69 \%)$ were female. The average age of onset was 39.6 years (range 13 to 70 ). Table II lists the events triggering the dystrophy, and the details of the surgical group are shown in Table III; their average number of operations on the affected knee before the precipitating procedure was 1.2 (range 0 to 3 ). Injuries or surgery about the patellofemoral joint were related to the onset of dystrophy in a total of 23 of 36 patients $(64 \%)$.

Six of the 36 patients $(17 \%)$ had evidence of a nerve injury about the knee. Two cases involved a peroneal nerve injury - one sustained at the time of high tibial osteotomy and the other following arthrotomy; both were confirmed by electromyography. Four patients sustained injuries to the infrapatellar branches of the saphenous nerve at the time of arthrotomy, resulting in neuroma formation.

Between the onset of symptoms and the time of diagnosis, an average of 1.6 (range 0 to 8 ) surgical procedures were performed on the affected knee or for the knee pain giving a total of 56 procedures in 36 patients (Table IV). One unfortunate woman who developed symptoms after a fall onto the front of her knee underwent successively, in a span of 33 months, diagnostic arthroscopy, three manipulations, arthroscopy and arthrotomy with patellofemoral realignment, posterior cruciate ligament reconstruction, manipulation, and total knee replacement. Her symptoms con- 
tinued unabated and the source was presumably unrecognised throughout this period of time.

Thirty-two of 36 patients $(89 \%)$ underwent diagnostic arthroscopy or arthrotomy following the onset of symptoms. The reported pathological findings were patellofemoral chondromalacia in 16 patients $(50 \%)$, neuroma of the infrapatellar branch of the saphenous nerve in four patients $(13 \%)$, patellofemoral tracking problems in five patients $(16 \%)$, meniscal tears in two patients $(6 \%)$ and an osteochondral defect of the medial femoral condyle in one patient $(3 \%)$. No intra-articular pathology was recognised in four patients $(13 \%)$.

Findings at diagnosis. The average delay from the onset of symptoms until the time of diagnosis was 29 months (range 3 weeks to 11 years). All patients complained of

Table IV. Surgery prior to diagnosis

\begin{tabular}{lc}
\hline Laminectomy & $\begin{array}{c}\text { Number of } \\
\text { procedures }\end{array}$ \\
Patellectomy & 2 \\
Diagnostic arthroscopy & 2 \\
Manipulation & 18 \\
Patellar debridement/realignment & 11 \\
\hline
\end{tabular}

Table V. Symptoms of reflex sympathetic dystrophy

\begin{tabular}{lll}
\hline & \multicolumn{2}{l}{ Patients affected } \\
\cline { 2 - 3 } Symptoms & Number & Per cent \\
\hline $\begin{array}{l}\text { Pain character } \\
\text { Aching } \\
\quad \text { Burning }\end{array}$ & 12 & 33 \\
Location & 24 & 67 \\
$\quad$ Anterior & & \\
$\quad$ Medial & 13 & 36 \\
$\quad$ Global & 3 & 8 \\
Night pain & 20 & 56 \\
Skin discoloration & 28 & 78 \\
Sensitivity to cold & 20 & 56 \\
Cutaneous hypersensitivity & 22 & 97 \\
\hline
\end{tabular}

Table VI. Distribution of osteopenia

\begin{tabular}{lll}
\hline & \multicolumn{2}{l}{ Knees } \\
\cline { 2 - 3 } Site & Number & Per cent \\
\hline Patella & 15 & 49 \\
Diffusely through the knee & 12 & 39 \\
Distal femur & 3 & 9 \\
Patella and distal femur & 1 & 3 \\
\hline
\end{tabular}

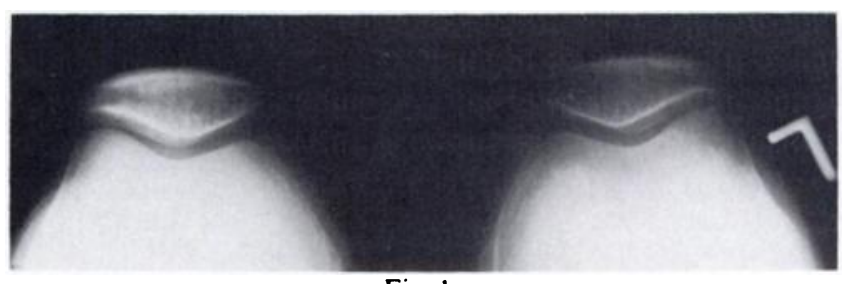

Fig. 1

Sky-line view of both knees reveals significant osteopenia in the patella of the knee affected by reflex sympathetic dystrophy.

pain at presentation. Sixteen of $36(44 \%)$ were using narcotic analgesics. Table $\mathrm{V}$ details the character and location of pain and the incidence of other physical findings. The initial pain rating scores averaged 12 points (range 0 to 25 points). Eighteen patients $(50 \%)$ were using weight-bearing assistive devices.

At the time of diagnosis, the average arc of movement of the affected knee was $93^{\circ}$ (range $5^{\circ}$ to $140^{\circ}$ ). Eleven patients presented with flexion contractures averaging $15^{\circ}$ (range $5^{\circ}$ to $45^{\circ}$ ).

Plain radiographs comparing both knees at or near the time of diagnosis were reviewed in all 36 patients; these radiographs were obtained at an average of 29 months following the onset of symptoms (range 6 weeks to 11 years). The typical series of views consisted of a long anteroposterior radiograph taken standing, and lateral and patellofemoral views of both knees (Fig. 1). Table VI details the distribution of osteopenia seen on the radiographs; this excluded the five patients who underwent total knee replacement before the onset of symptoms, for whom objective evidence of osteopenia was no longer available.

In the 13 patients $(36 \%)$ on whom scintigraphy was performed at the time of diagnosis, the average interval between the onset of symptoms and scintigraphy was 13.8 months (range 5 to 36 months). Late-phase scans showed diffuse uptake about the knee in six patients $(46 \%)$, while increased uptake was limited to the patella in two of 13 scans $(15 \%)$. Five scans were interpreted as normal $(39 \%)$.

In eight patients, thermograms revealed an average temperature decrease of $1.6^{\circ} \mathrm{C}$ (range $1.0^{\circ}$ to $2.5^{\circ} \mathrm{C}$ ) in the affected lower limb.

Long-term results following sympathetic block and sympathectomy. When the constellation of symptoms strongly suggested a diagnosis of reflex sympathetic dystrophy, patients then underwent lumbar sympathetic block. This was done in all patients. The average time interval between the onset of symptoms and initial sympathetic block was 29 months (range 3 months to 10 years). In general, blocks were performed within eight weeks of presentation and consisted of a series of three or four blocks over a span of three to five days. A good result following lumbar sympathetic block or sympathectomy was defined as relief of at least $75 \%$ of the pain. A fair 
Table VII. Results of sympathetic block and resection

\begin{tabular}{lll}
\hline & \multicolumn{2}{l}{ Patients } \\
\cline { 2 - 3 } & Number & Per cent \\
\hline $\begin{array}{l}\text { Sympathetic block } \\
\text { Good } \\
\text { Fair }\end{array}$ & 21 & 58 \\
Recurrence of symptoms & 15 & 42 \\
$\begin{array}{l}\text { Sympathectomy } \\
\text { Good } \\
\text { Fair }\end{array}$ & 32 & 89 \\
\hline
\end{tabular}

Table VIII. Influence of duration of symptoms on results of treatment

\begin{tabular}{lllc}
\hline $\begin{array}{l}\text { Results of } \\
\text { treatment }\end{array}$ & $\begin{array}{l}\text { Group I } \\
(n=10)\end{array}$ & $\begin{array}{l}\text { Group II } \\
(n=10)\end{array}$ & $\begin{array}{l}\text { Group III } \\
(n=16)\end{array}$ \\
\hline $\begin{array}{l}\text { Sympathetic block } \\
\text { Good }\end{array}$ & 10 & 5 & 6 \\
$\quad \begin{array}{l}\text { Fair } \\
\text { Permanent }\end{array}$ & 0 & 5 & 10 \\
Sympathectomy & 3 & 1 & 1 \\
\hline
\end{tabular}

result was defined as definite improvement, but less than $75 \%$ relief. Table VII details the results of sympathetic block and sympathectomy. Recurrence of symptoms occurred in 32 patients $(89 \%)$ after sympathetic block: in 18 , symptoms recurred within one week of the final block; in 14, relapse occurred later, averaging 12 weeks after the final block (range 3 weeks to 11 months). Nine patients refused lumbar sympathectomy. In the 23 patients who underwent sympathectomy, the result was classified as good in $15(65 \%)$ and fair in eight $(35 \%)$. The degree of pain relief in all patients undergoing sympathectomy paralleled the degree of relief following sympathetic block. The average time interval from the onset of symptoms to sympathectomy averaged 32 months (range 2 months to 11 years).

Long-term follow-up from the time of initial sympathetic intervention averaged 4.3 years (range 2 to 11 years). At follow-up, nine patients $(25 \%)$ complained of a cold sensation about the knee (before treatment this was $97 \%$ ), while 12 patients $(33 \%)$ complained of cutaneous hypersensitivity (before treatment $55 \%$ ). Skin mottling and bluish discoloration were present in five patients $(14 \%)$ (before treatment $55 \%$ ). The range of movement of the affected knee at the time of last physical examination averaged $98^{\circ}$ (range $20^{\circ}$ to $140^{\circ}$ ) (before treatment $93^{\circ}$ ). Follow-up pain scores averaged 32 points (range 0 to 50 points) (before treatment 12 points). At long-term follow-up, 19 patients (53\%) reported taking no medication for pain, while eight patients $(22 \%)$ were taking narcotic analgesics (before treatment $49 \%$ ).

Recurrence of dystrophy after surgery for co-existent mechanical derangement. Twenty-three of 36 patients $(64 \%)$ had mechanical derangements of the knee. Of these, 17 underwent a total of 27 procedures on the knee after they had undergone sympathetic block or sympathectomy. Care was taken to wait until symptoms of reflex sympathetic dystrophy had subsided before performing these procedures. The average time interval between sympathetic intervention and the first procedure to correct mechanical derangement was five months (range 2 to 17 months). Eight of 17 patients $(47 \%)$ had recurrence of sympathetic dystrophy after these procedures: in these eight, the average time from sympathetic intervention to the initial procedure was four months, while for the remaining nine patients it was seven months.

Effect of delay in performing sympathetic intervention. In order to determine whether the results of sympathetic block or sympathectomy were related to the time span between the onset of symptoms and the initial sympathetic blockade, the patients were arranged into three groups for analysis: Group I consisted of 10 patients who underwent initial sympathetic blockade within one year of onset of symptoms, in Group II (also 10 patients) the interval was 12 to 24 months, and in Group III (16 patients) it was at least two years. Comparable follow-up was available for all groups. Table VIII and Figure 2 detail the findings. Using statistical analysis, a comparison was made between the three groups: Group I had a

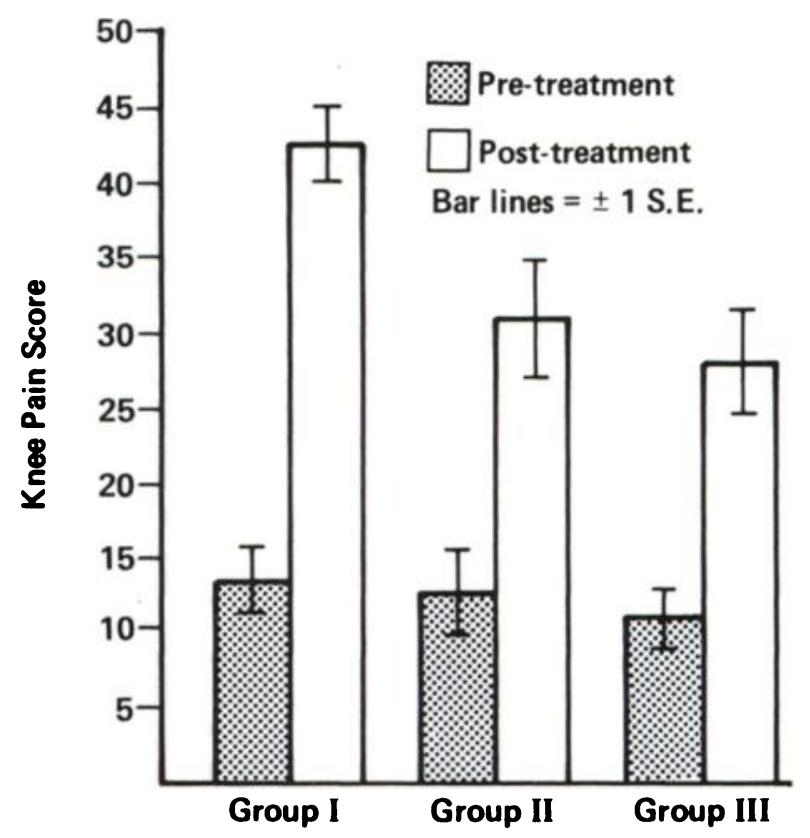

Group I: Initial sympathetic intervention within 12 months of onset of RSD symptoms

Group II: Initial sympathetic intervention 12-24 months after onset of RSD symptoms

Group III: Initial sympathetic intervention over 24 months after onset of RSD symptoms

Fig. 2

Results following sympathetic intervention. A high score implies less pain. 


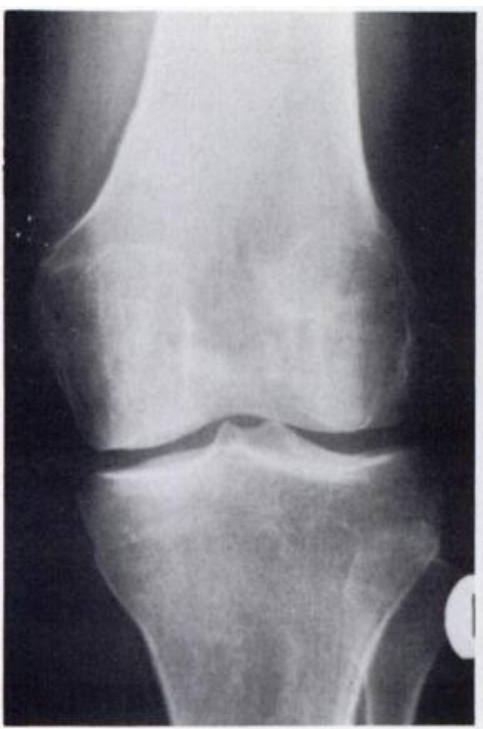

Fig. 3

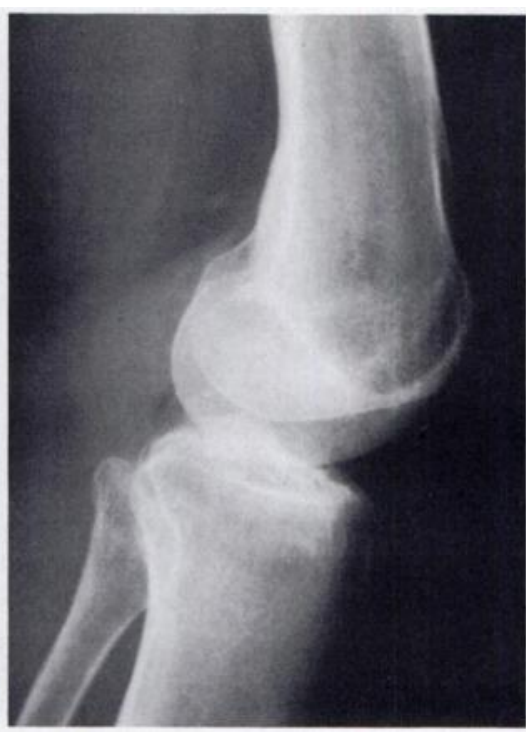

Fig. 4

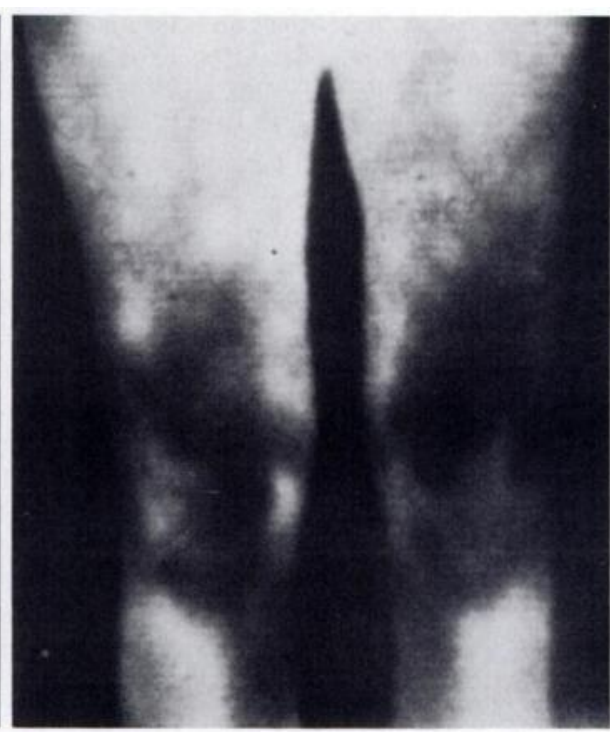

Fig. 5

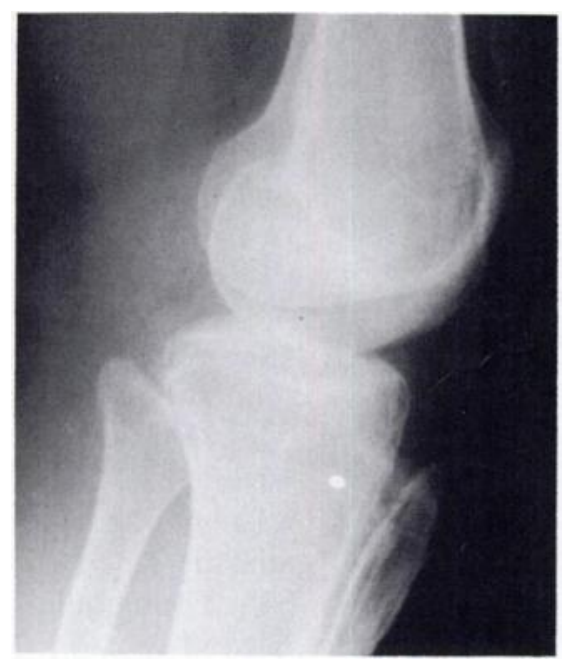

Fig. 6

Case 1. Figures 3 and 4 - Radiographs of the left knee eight months after onset of vasomotor symptoms demonstrate osteopenia of the distal femur. Figure 5 - Anteroposterior thermogram demonstrating a $2^{\circ} \mathrm{C}$ temperature decrease in the left knee. Figure 6 Lateral radiograph 52 months after sympathectomy and 46 months after tibial tubercle elevation reveals resolution of osteopenia.

significantly better $(p<0.05)$ final pain score and result from sympathetic intervention than Groups II or III.

\section{ILLUSTRATIVE CASE REPORTS}

Case 1. A 39-year-old woman with malunion after a patellar fracture had a patellectomy. Soon afterwards she developed persistent burning pain about the anterior aspect of her knee, associated with marked cutaneous hypersensitivity and bluish skin coloration. These symptoms prevented her from returning to work. Upon presentation to our clinic eight months later her knee demonstrated a range of movement from $0^{\circ}$ to $130^{\circ}$, marked cutaneous hypersensitivity and decreased skin temperature with bluish discoloration. Her pain score was 10 out of a possible 50 points. Radiographs (Figs 3 and 4) revealed osteopenia of the distal femur. A technetium bone scan showed diffuse uptake about the knee. Thermograms revealed a $2^{\circ} \mathrm{C}$ decrease in the affected limb (Fig. 5).

Lumbar sympathetic block provided transient relief from her vasomotor and pain symptoms. Ten months after patellectomy she underwent lumbar sympathectomy which gave $80 \%$ relief but anterior knee pain continued. Six months after sympathectomy a tibial tubercle elevation was performed in an effort to improve knee extension and gave good relief from pain with no recurrence of sympathetic dystrophy. Fifty-two months after sympathectomy, she reported only occasional burning sensation in the knee and radiographs revealed resolution of the osteopenia (Fig. 6). She had no cutaneous hypersensitivity and movements were from $0^{\circ}$ to $130^{\circ}$. Her final pain score was 40 out of 50 possible points, and she was working full time.

Case 2. A 16-year-old girl sustained a valgus, twisting injury to her left 
knee while cheerleading; she had an arthrotomy and meniscectomy which was complicated by a peroneal nerve palsy. Postoperatively, she complained of persistent ache in the knee, associated with cutaneous hypersensitivity, cold intolerance and bluish mottling about the knee. Subsequently, she underwent a joint debridement. Over the next four years she had diagnostic arthroscopy and open lysis of adhesions. During this period her peroneal palsy improved but her other knee symptoms persisted.

When first seen by us 66 months after the onset of symptoms of sympathetic dystrophy, she complained of diffuse aching in the knee, cutaneous hypersensitivity and cold intolerance. There was bluish mottling of the skin about the knee which was shiny, smooth, and extremely sensitive to light touch. Painful movement measured $20^{\circ}$ to $40^{\circ}$ and the quadriceps was markedly atrophic. She required crutches and a knee immobiliser with a drop-foot brace. Narcotic analgesics were required for pain relief, and she was unable to work. Radiography (Fig. 7) revealed osteopenia about the proximal tibia, patella and distal femur. Thermograms revealed a $2 \mathrm{C}$ decrease about the knee and lower leg. No bone scan was obtained. The initial pain and disability score was 0 out of a possible 50 points.

Sixty-eight months after the onset of symptoms the patient underwent a series of lumbar sympathetic blocks which provided approximately $50^{\circ}$ relief of pain and vasomotor symptoms for a period of six weeks. After recurrence of her symptoms, a lumbar sympathectomy was performed which provided a similar degree of relief for a longer period of time. Three months later open lysis of adhesions and manipulation were performed to increase her range of movement. Following this procedure, pain and vasomotor symptoms recurred. Subsequently, she underwent posterior capsulotomy, and peroneal nerve release with no significant improvement in movement, vasomotor symptoms, or pain. Electrical stimulation also failed. Ultimately, she underwent knee fusion because of painful instability and pain caused by the required orthosis. At 51 months after sympathectomy and 10 years after the onset of sympathetic dystrophy she still reported cutaneous hypersensitivity and moderate aching about her knee. However, she was able to walk without assistive devices and was taking no narcotic analgesics regularly. Her pain and function score was 25 out of a possible 50 points.

\section{DISCUSSION}

Despite several excellent reviews on reflex sympathetic dystrophy in recent years, this disorder is seldom included in the differential diagnosis of the painful knee (Patman et al. 1973; Lankford and Thompson 1977; Shutzer and Gossling 1984). According to Plewes (1956) sympathetic dystrophy will occur to some extent in one of every 2000 accidents involving an extremity. Nevertheless, in Patman's (1973) series of 113 patients with sympathetic dystrophy, in only 18 was the diagnosis made by the initial physician.

In our series, $64 \%$ of patients had an associated patellofemoral derangement or injury. Ficat and Hungerford (1977) noted that the patellofemoral joint was invariably involved in all their patients with dystrophy affecting the knee; the superficial subcutaneous portion of the patella renders it particularly vulnerable to injury, which explains the association. It is also possible that the same trauma which unleashes the sympathetic discharge and its pathological consequences may also be the origin of more obvious mechanical derangement such as subluxation, fracture, or osteochondral injury.

Mild stiffness was present in most of our patients, as

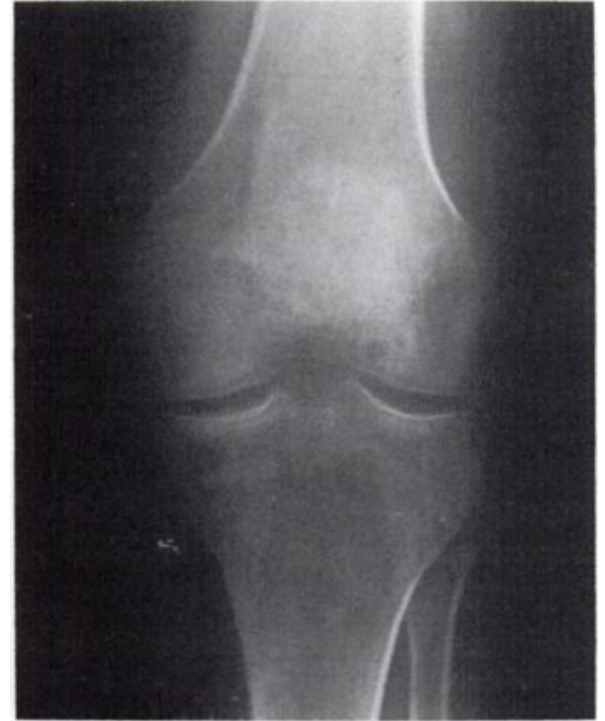

Fig. 7

Case 2. An anteroposterior radiograph 5.5 years after the onset of symptoms of sympathetic dystrophy reveals marked osteopenia about the affected left knee.

the overall range of movement at the time of diagnosis was $93^{\circ}$. This differs from the findings of marked stiffness in patients with sympathetic dystrophy involving the hand (Kozin et al. 1981; Lagier et al. 1983). According to Ficat and Hungerford (1977) even mild limitation of movement should not be seen in patients with isolated chondromalacia or the patellofemoral arthralgias. This characteristic stiffness should help to distinguish sympathetic dystrophy from these other disorders.

Technetium bone scintigraphy and thermography proved valuable diagnostic aids in our series. Our $61 \%$ incidence of positive scintigraphic delayed images in the patients who underwent imaging is less than the $96 \%$ incidence reported by Mackinnon and Holder (1984) in a study involving the hand and wrist joints: they maintained that a strictly interpreted delayed radionuclide image revealing juxta-articular activity can be diagnostic for reflex sympathetic dystrophy. In a similar study, Kozin et al. (1981) reported positive scan findings in $60 \%$ of patients with hand involvement. To our knowledge, no similar study has addressed involvement of the lower limb. All the patients who underwent thermography revealed cutaneous temperature decreases in excess of $1^{\circ} \mathrm{C}$ in a non-dermatomal pattern about the affected knee. Uematsu et al. (1981) and Ecker (1984) have documented the usefulness of thermography in evaluating chronic pain syndromes. While not diagnostic, thermography provides useful information on sympathetic disturbances.

Excluding those whose symptoms followed total knee replacement, $100 \%$ of our patients demonstrated radiographic evidence of osteopenia in the affected knee. 
The patella was involved in $80 \%$ of these patients. Similar findings have been noted by Arlet et al. (1981). The pathophysiology of osteopenia, a well-known finding in sympathetic dystrophy (Miller and de Takats 1942; Casten and Betcher 1955; de Takats 1965), has been described by Lagier et al. (1983) who presented histological evidence of Sudeck's atrophy in a patient with knee involvement, revealing vascular dilatation, oedema and fibrosis of the fatty marrow, and some remodelling: Basle, Rebel and Renier (1983) noted the same changes. Arlet et al. (1981) noted thinning of cortical bone, trabecular rarefaction and marrow fibrosis in biopsies taken from affected bones.

The sine qua non for diagnosis, as well as the mainstay of treatment in our series, was lumbar sympathetic block. Toumey (1948) as well as Patman et al. (1973) noted that a positive response to sympathetic block was the most important diagnostic criterion in the evaluation of sympathetic dystrophy. Our finding that the amount of relief afforded by sympathetic blocks correlated with the relief obtained from sympathectomy was also noted by Toumey (1948).

Physiotherapy with analgesic support and sympatholytic pharmacological agents are also important in treatment (Kleinert et al. 1973; Poplawski, Wiley and Murray 1983; Shutzer and Gossling 1984). In early mild cases, sympatholytic medications and carefully supervised physiotherapy may avert the need for sympathetic blocks (Shutzer and Gossling 1984). Most of our patients, however, had severe, longstanding involvement. We found that when sympathetic intervention was initiated within one year of the onset of symptoms, significantly better results were obtained. This is in agreement with studies in the hand (Kleinert et al. 1973; Lankford and Thompson 1977; Poplawski et al. 1983).

It should be noted that our series of patients, like that of Arlet et al. (1981), deals with involvement of only part of the extremity. This differs from reports where the entire extremity is involved or there is only distal involvement. Helms, O'Brien and Katzberg (1980), however, have reported segmental dystrophy in the upper limb. Thus, the diagnosis of sympathetic dystrophy should not be excluded merely because an intermediate joint is the focus of the disorder.

The psychological and social problems have been difficult to analyse. Numerous authors have drawn attention to the characteristic personality as being dependent, over-reactive, and often hostile to the physician (Miller and de Takats 1942; Patman et al. 1973; Lankford and Thompson 1977). In our retrospective study, however, we could draw no conclusions regarding a psychological or social profile.

\section{REFERENCES}

Arlet J, Ficat P, Durroux R, Girou de Gercouri R. Histopathologie des lesions osseuses et cartilagineuses dans l'algodystrophie sympathique réflexe du genou: a propos de 16 observations. Rev Rhum Mal Osteoartic 1981:48:325-21. (Eng. abstr.)

Basle MF, Rebel A, Renier JC. Bone tissue in reflex sympathetic dystrophy syndromes - Sudeck's atrophy: structural and ultrastructural studies. Metab Bone Dis Relat Res 1983;4:305-11.

Casten DF, Betcher AM. Reflex sympathetic dystrophy. Surg Gynecol Obstet 1955;100:97-101.

De Takats G. Sympathetic reflex dystrophy. Med Clin North Am 1965:49:117-29.

Doupe J, Cullen CH, Chance GQ. Post-traumatic pain and causalgic syndrome. J Neurol Neurosurg Psychiatry 1944:7:33-48.

Ecker A. Thermography in the diagnosis of reflex sympathetic dystrophy (letter). NY State J Med 1984:84:6.

Evans JA. Reflex sympathetic dystrophy. Surg Gynecol Obstet 1946;82:36-43.

Ficat RP, Hungerford DS. Disorders of the patello-femoral joint. Paris : Masson, 1977.

Helms CA, O'Brien ET, Katzberg RW. Segmental reflex sympathetic dystrophy syndrome. Radiology 1980;135:67-8.

Kleinert HE, Cole NM, Wayne L, et al. Post-traumatic sympathetic dystrophy. Orthop Clin North Am 1973;4:917-27.

Kozin F, Ryan LM, Carerra GF, Soin JS, Wortmann RL. The reflex sympathetic dystrophy syndrome (RSDS): III. Scintigraphic studies, further evidence for the therapeutic efficacy of systemic corticosteroids, and proposed diagnostic criteria. Am J Med $1981: 70: 23-30$

Lagier R, Boussina I, Mathies B. Algodystrophy of the knee : anatomoradiological study of a case. Clin Rheumatol 1983;2:71-7.

Lankford LL, Thompson JE. Reflex sympathetic dystrophy, upper and lower extremity: diagnosis and management. Am Acad Orthop Surg Instr Course Lect 1977:26:163-78.

Livingston WK. Pain mechanisms: a physiologic interpretation of causalgia and its related states. New York: Macmillan, 1943.

Mackinnon SE, Holder LE. The use of three-phase radionuclide bone scanning in the diagnosis of reflex sympathetic dystrophy. $J$ Hand Surg $[\mathrm{Am}]$ 1984;9:556-63.

Melzack R, Wall PD. Pain mechanisms: a new theory. Science 1965:150:971-9.

Miller DS, de Takats G. Posttraumatic dystrophy of the extremities : Sudeck's atrophy. Surg Gynecol Obstet 1942;75:558-82.

Mitchell SW, Morehouse GR, Keen WW. Gunshot wounds and other injuries of nerves. Philadelphia: JB Lippincott, 1864.

Patman RD, Thompson JE, Persson AV. Management of posttraumatic pain syndromes: report of 113 cases. Ann Surg 1973:177:780-7.

Plewes LW. Sudeck's atrophy in the hand. J Bone Joint Surg $[\mathrm{Br}]$ 1956:38-B:195-203

Poplawski ZJ, Wiley AM, Murray JF. Post-traumatic dystrophy of the extremities: a clinical review and trial of treatment. $J$ Bone Joint Surg $[A m]$ 1983;65-A :642-55.

Shutzer SF, Gossling HR. The treatment of reflex sympathetic dystrophy syndrome. J Bone Joint Surg [Am] 1984:66-A :625-9.

Spurling RG. Causalgia of upper extremity: treatment by dorsal sympathetic ganglionectomy. Arch Neurol \& Psychiat 1930;23:784-8.

Toumey JW. Occurrence and management of reflex sympathetic dystrophy (causalgia of the extremities). J Bone Joint Surg 1948;30:883-94.

Uematsu S, Hendler N, Hungerford DS, Long D, Ono N. Thermography and electromyography in the differential diagnosis of chronic pain syndromes and reflex sympathetic dystrophy. Electromyogr Clin Neurophysiol $1981 ; 21: 165-82$. 